\title{
Lipid Management and 2-Year Clinical Outcomes in Japanese Patients with Acute Coronary Syndrome: EXPLORE-J
}

\author{
Masato Nakamura ${ }^{1}$, Junya Ako ${ }^{2}$, Hidenori Arai $^{3}$, Atsushi Hirayama ${ }^{4}$, Atsushi Nohara ${ }^{5}$, Yoshitaka Murakami ${ }^{6}$, \\ Asuka Ozaki ${ }^{7}$ and Mariko Harada-Shiba ${ }^{8}$
}

${ }^{1}$ Division of Cardiovascular Medicine, Toho University Ohashi Medical Center, Tokyo, Japan

${ }^{2}$ Department of Cardiovascular Medicine, Kitasato University, Kanagawa, Japan

${ }^{3}$ National Center for Geriatrics and Gerontology, Aichi, Japan

${ }^{4}$ Cardiovascular Division, Osaka Police Hospital, Osaka, Japan

${ }^{5}$ Department of Clinical Genetics, Ishikawa Prefectural Central Hospital, Kanazawa, Ishikawa, Japan

${ }^{6}$ Department of Medical Statistics, Toho University, Ota-ku, Tokyo, Japan

${ }^{7}$ Sanofi K.K., Tokyo, Japan

${ }^{8}$ Department of Molecular Innovation in Lipidology, National Cerebral \& Cardiovascular Center Research Institute, Osaka, Japan

Aim: The prevalence of atherosclerotic cardiovascular (CV) disease has risen in Japan due to increasing metabolic risk factors, including dyslipidemia. A positive linear correlation between low-density lipoprotein cholesterol (LDL-C) levels, incidence of CV events, and preventive effects of lipid-lowering therapy (LLT) is well established; however, data in Japan are limited. This analysis evaluated current lipid management practices and risk of recurrent $\mathrm{CV}$ events in Japanese post-acute coronary syndrome (ACS) patients.

Methods: EXPLORE-J is a multicenter, 2-year observational study of hospitalized ACS patients in Japan.

Results: At 2-year follow-up ( $n=1944$, mean age 66 years, $80.3 \%$ male), the cumulative incidence of major adverse cardiovascular events (MACE; death associated with myocardial infarction/cerebrovascular accident [CVA] and other CV death, non-fatal ACS, and non-fatal CVA requiring hospitalization during the observation period) was $6.2 \%$; respective incidences of $\mathrm{CV}$ death, non-fatal ACS, and CVA were $0.7 \%$, $4.5 \%$, and $1.7 \%$. Statin, intensive statin, and ezetimibe were prescribed for $93.6 \%, 8.2 \%$, and $3.9 \%$ at visit (V) 1 (Day[D]1 + 14), and $92.3 \%, 10.5 \%$, and $11.6 \%$ of patients at V5 (D730 \pm 30 days), respectively. Mean LDL-C was reduced from first post-ACS measurement $(121.3 \mathrm{mg} / \mathrm{dL})$ to $\mathrm{V} 5(79.8 \mathrm{mg} / \mathrm{dL})$. A limited number of patients achieved LDL-C $<70 \mathrm{mg} / \mathrm{dL}$ from V1-V5 (14.4\%-34.6\%); those with a greater LDL-C reduction by V1 had a lower probability of MACE, indicating the benefits of early LDL-C reduction post ACS.

Conclusions: Guideline-recommended LDL-C target achievement post ACS in Japan is suboptimal, suggesting the need for LLT intensification. Additional analyses by risk stratification of the study population and the benefits of lipid management are planned.

Key words: Cardiovascular disease, Acute coronary syndrome, Major adverse cardiovascular events, Lipid-lowering therapy, Japan

\section{Introduction}

Despite a lower cardiovascular (CV) event rate than in Western countries, similar to other territories, the prevalence of atherosclerotic cardiovascular disease
(ASCVD) in Japan, particularly high-risk ASCVD, and the associated healthcare burden have risen in recent years ${ }^{1}$. This partly reflects the aging of the population and partly the growing adoption of a Western lifestyle that has resulted in an increase in

Address for correspondence: Masato Nakamura, Division of Cardiovascular Medicine, Toho University, Ohashi Medical Center, Tokyo, Japan

E-mail: masato@oha.toho-u.ac.jp

Received: July 29, 2020 Accepted for publication: December 23, 2020

Copyright@2021 Japan Atherosclerosis Society

This article is distributed under the terms of the latest version of CC BY-NC-SA defined by the Creative Commons Attribution License. 
metabolic risk factors, including dyslipidemia, a key promoter of atherosclerosis ${ }^{2)}$. ASCVD encompasses a spectrum of clinical manifestations of atherosclerosis, including ischemic stroke, peripheral artery disease $(\mathrm{PAD})$, and coronary artery disease $(\mathrm{CAD})^{3,4)}$. Importantly, patients with ASCVD, particularly those following a recent stroke or acute coronary syndrome (ACS), are at high risk of recurrent ischemic events and CV mortality ${ }^{5,6)}$.

An abundance of data from global trials of lipidlowering therapies (LLTs) ${ }^{7)}$ has demonstrated a positive association between hypercholesterolemia and the incidence of CAD. Conversely, data have demonstrated low-density lipoprotein cholesterol (LDL-C) lowering and reduced CV events with intensive statin therapy ${ }^{8)}$; and, in high-risk patients, additional LLT with ezetimibe ${ }^{9)}$ and/or a proprotein convertase subtilisin/kexin type 9 (PCSK9) inhibitor ${ }^{10,11)}$. Results from the ESTABLISH study in Japan showed that when aggressive statin therapy is started early (within 48 hours of an ACS event) and continued for 6 months, this significantly reduced plaque volume, with the percent change in plaque volume significantly associated with percent LDL-C reduction regardless of baseline LDL-C ${ }^{12}$. Early initiation of statin therapy in post-ACS patients also improved long-term clinical outcomes ${ }^{13)}$; however, data from real-world clinical practice in Japan are limited.

The prospective, observational EXPLORE-J study in Japan was conducted to gain insights into the association between LDL-C management and the CV risk of Japanese patients with $\mathrm{ACS}^{14)}$. At the time of this study (2015/2016), the 2012 Japan Atherosclerosis Society (JAS) guidelines ${ }^{15)}$ recommended lowering LDL-C to $<100 \mathrm{mg} / \mathrm{dL}$ for high-risk patients with established CAD, with statins as the first-line treatment option, and combination or alternative therapy with a non-statin LLT (resin, probucol, eicosapentaenoic acid [EPA], and/or ezetimibe). The American College of Cardiology/American Heart Association ${ }^{16)}$ and the European Society of Cardiology (ESC)/European Atherosclerosis Society (EAS) ${ }^{5}$ 17) lipid management guidelines at the time specified a lower LDL-C goal $(<70 \mathrm{mg} / \mathrm{dL})$ and at least a $50 \%$ LDL-C reduction, using intensive statin therapy and additional LLT with ezetimibe and/or a PCSK9 inhibitor to reduce the risk of CV morbidity and mortality in high-risk patients, including those with ACS. Previously presented results from EXPLORE-J ${ }^{14)}$ focused on the prevalence of familial hypercholesterolemia ${ }^{18)}$ as well as the background characteristics of these patients, including comorbidities and metabolic status ${ }^{19)}$. Here, we present results from the EXPLORE-J study obtained from investigating the association between the current status of lipid management and the risk of recurrent $\mathrm{CV}$ events over 2 years in Japanese post-ACS patients.

\section{Aim}

To determine LLT use and risk of recurrent CV events in post-ACS patients in Japan, where the prevalence of atherosclerotic CV disease has increased in recent years yet lipid management practices are not clear.

\section{Methods}

\section{Study Design}

Details of the study design and methods of this 2-year, multicenter, prospective, observational study of Japanese patients presenting with ACS at 59 sites in Japan have been reported previously ${ }^{14,}{ }^{19)}$. In brief, 2016 patients enrolled consecutively required hospitalization for ACS during the enrolment period from April 2015 to August 2016 were registered at 59 sites and followed-up for 2 years (Fig. 1).

The study was conducted in compliance with the Declaration of Helsinki (amended in October 2013) and the Ethical Guidelines for Medical and Health Research Involving Human Subjects (enacted on December 22, 2014). The study protocol was approved by each participating clinical site's respective ethical review committee prior to study commencement. All patients provided written informed consent, and patient anonymity is protected.

\section{Study Participants}

Study inclusion criteria were as follows: Japanese patients aged $\geq 20$ years hospitalized for any ACS (ST-segment-elevation myocardial infarction [STEMI], non-STEMI, or unstable angina [UA]), who provided written informed consent within 7 days of hospitalization. Key exclusion criteria were as follows: chest pain and coronary artery disease associated with prespecified concomitant serious diseases; in-stent thrombosis; enrollment in other investigational studies with interventions that could affect lipid profiles, such as clinical trials with LLTs; and a judgment of being inappropriate for inclusion from the investigators or subinvestigators based on observations of the presence of characteristics that may interfere with the natural course of ACS.

\section{Background Characteristics}

Patient background data, including demographic characteristics, physical findings, laboratory data, and medical history, were collected within 14 days of 


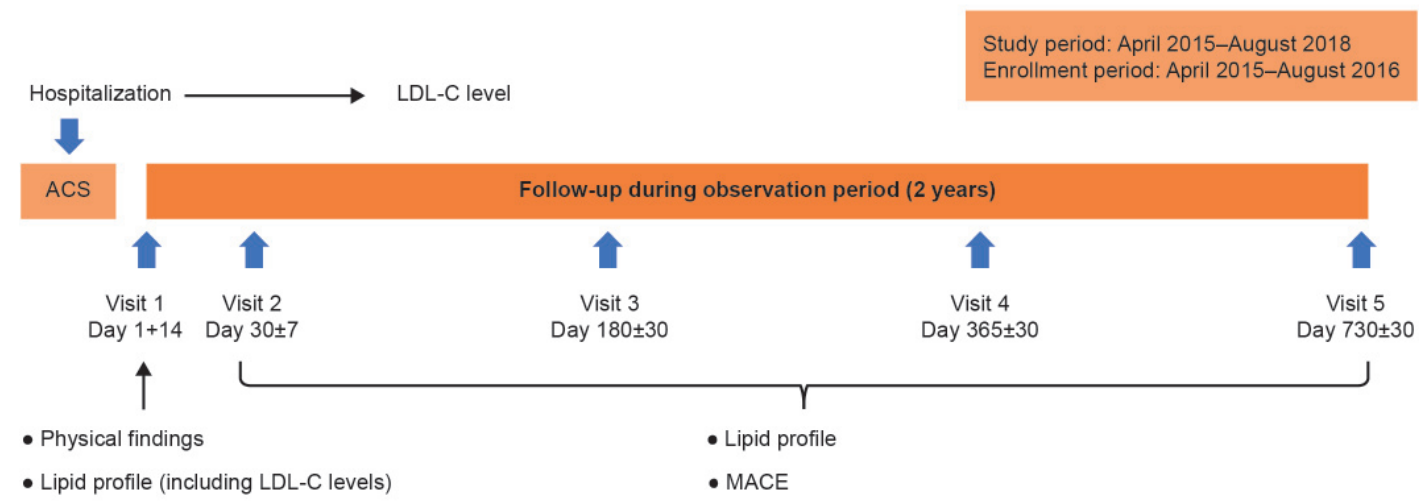

Fig. 1. Study design

ACS, acute coronary syndrome; LDL-C, low-density lipoprotein cholesterol; MACE, major adverse cardiovascular events.

hospitalization (at Visit 1) from electronic case report forms, as described previously ${ }^{14)}$. The presence of a comorbidity was determined at the discretion of the attending/reporting physician.

\section{Lipid Profile}

The first LDL-C measurement following hospitalization was reported. LDL-C levels (direct and calculated) and other lipid parameters were obtained at Visit 1 (within 14 days of hospitalization for ACS [Day $1+14]$ ), and at subsequent visits, Visit 2 (Day $30 \pm 7$ ), Visit 3 (Day 180 \pm 30 ), Visit 4 (Day $365 \pm$ 30 ), and Visit 5 (Day $730 \pm 30$ ). LDL-C levels post ACS were assessed according to the type of LLT (any LLT, statin, intensive statin therapy, PCSK9 inhibitors, fibrates, ezetimibe, or EPA/docosahexaenoic acid [DHA]).

\section{Study Endpoints}

The primary endpoint was the incidence of major adverse $\mathrm{CV}$ events (MACE) during the period from hospitalization for ACS and the subsequent 2-year observation period. MACE were defined as death associated with myocardial infarction (MI)/ cerebrovascular accident (CVA) or other CV death, non-fatal ACS (MI or hospitalization for UA), and non-fatal CVA requiring hospitalization during the observation period.

Secondary endpoints included treatment rate by LLT (based on written prescriptions), including any statin therapy; intensive statin therapy (atorvastatin $20 \mathrm{mg}$, rosuvastatin $\geq 10 \mathrm{mg}$, and pitavastatin $4 \mathrm{mg}$ ); a PCSK9 inhibitor; fibrates; ezetimibe; or EPA/DHA. Other secondary endpoints included the lipid profile (LDL-C, total cholesterol, high-density lipoprotein cholesterol (HDL-C), non-HDL-C, and triglycerides) from Visits 1 to 5; the incidence of any outcome event (defined as coronary revascularization based on myocardial ischemia, non-coronary revascularization, inpatient treatment due to the occurrence or exacerbation of heart failure, transient ischemic attack [TIA], acute arterial obstruction, central retinal artery occlusion, or other adverse events prolonging or requiring hospitalization) during the period from hospitalization for ACS and the subsequent 2-year observation period; and probability of MACE by LDL-C reduction category from the first measurement after ACS to Visits 1 (Day $1+14$ days) and 3 (Day $180 \pm 30$ days).

\section{Statistical Analysis}

The sample size was calculated based on a previous study in Japanese patients with ACS, the Prevention of Atherothrombotic Incidents Following Ischemic Coronary attack (PACIFIC) registry ${ }^{20)}$. In the PACIFIC registry, the incidence of MACE was $6.4 \%$ at 2 years $^{21)}$, hence the planned sample size was 2000 patients with an estimated precision of $\pm 1 \%$ in the incidence of MACE with a 95\% confidence interval (CI) of $5.3 \%-7.4 \%$.

Patient demographics and background characteristics are presented as the mean, median, standard deviation, range for continuous data, and number and proportion of subjects in each category for categorial data.

The primary endpoint (the incidence of MACE at 2 years) of the first event after registration was described by Kaplan-Meier curves, and their 95\% CI was determined by the Greenwood formula.

Subgroup analyses for the probability of MACE were conducted by baseline LDL-C ( $<70$ vs. $\geq 70$ $\mathrm{mg} / \mathrm{dL}$ ) and quartile of absolute and percent LDL-C change; $P$-values were calculated using the log-rank test. Additionally, Cox proportional hazards models 
Table 1. Patient baseline characteristics

\begin{tabular}{|c|c|c|}
\hline & Patients, $N$ & $n(\%)^{\S}$ \\
\hline Age, years, mean (SD) & 1944 & $66.0(12.2)$ \\
\hline Male & 1944 & $1561(80.3)$ \\
\hline BMI, $\mathrm{kg} / \mathrm{m}^{2}$, mean $(\mathrm{SD})$ & 1937 & $24.2(3.6)$ \\
\hline ACS type & 1944 & \\
\hline STEMI & & $1195(61.5)$ \\
\hline UA & & $440(22.6)$ \\
\hline Non-STEMI & & $309(15.9)$ \\
\hline $\mathrm{eGFR}<15 \mathrm{~mL} / \mathrm{min} / 1.73 \mathrm{~m}^{2}$ & 1883 & $41(2.2)$ \\
\hline \multicolumn{3}{|l|}{ Lipids, mg/dL, mean $(\mathrm{SD})^{\#}$} \\
\hline $\mathrm{LDL}_{-} \mathrm{C}^{\dagger}$ & 1827 & $121.3(40)$ \\
\hline LDL-C (calculated) & 1767 & $99.4(31.9)$ \\
\hline HDL-C & 1831 & $41.1(11.7)$ \\
\hline Non-HDL-C & 1788 & $123.8(35.9)$ \\
\hline Triglycerides, median (min, max) & 1838 & $109.0(22,967)$ \\
\hline Total cholesterol & 1803 & $165.2(38.4)$ \\
\hline History of CV risk factors/comorbidities & 1944 & \\
\hline Dyslipidemia & & $1512(77.8)$ \\
\hline Hypertension & & $1427(73.4)$ \\
\hline Diabetes mellitus & & $679(34.9)$ \\
\hline \multicolumn{3}{|l|}{ Smoking } \\
\hline Current smoker & & $739(38.0)$ \\
\hline Previous smoker & & $541(27.8)$ \\
\hline None & & $664(34.2)$ \\
\hline Coronary artery disease & & $355(18.3)$ \\
\hline Cerebrovascular accident & & $149(7.7)$ \\
\hline Dialysis & & $38(2.0)$ \\
\hline Peripheral artery disease & & 37 (1.9) \\
\hline \multicolumn{3}{|c|}{$\begin{array}{l}{ }^{8} \text { Unless otherwise specified. } \\
\text { "At visit } 1 . \\
\text { At first measurement after hospitalization. } \\
\text { ACS, acute coronary syndrome; BMI, body mass index; CV, cardiovascular; eGFR, estimatec } \\
\text { glomerular filtration rate; HDL-C, high-density lipoprotein cholesterol; LDL-C, low-density } \\
\text { lipoprotein cholesterol; SD, standard deviation; STEMI, ST-segment-elevation myocardia } \\
\text { infarction; UA, unstable angina. }\end{array}$} \\
\hline
\end{tabular}

were used to adjust for potential confounding factors. All potential confounders that were used in CREDOKyoto risk score were employed. In our data, previous history of both peripheral artery and CAD were highly correlated with hypertension, hence these two risk factors were included instead of hypertension in the Cox model. Albumin was not included in the Cox model because we did not have this data.

LDL-C values from Visits 1 to 5 were calculated using the Friedwald formula. ${ }^{22}$. Further analysis of the secondary endpoints (MACE developed by Visit 2 and between Visits 2 and 5) and treatment rate by LLT were assessed by determining the ratio of subjects on each LLT administered during observation using the full analysis set.

\section{Results}

\section{Baseline Characteristics}

Of 2016 registered patients at 59 facilities, 1944 were included in this analysis. The most common reason for patient exclusion $(n=72)$ was failure to obtain informed consent within the stipulated time $(n=62 \text {; Supplementary Fig. } 1)^{19)}$.

Patients' baseline mean age was 66.0 years, $80.3 \%$ were male, and mean body mass index (BMI) was $24.2 \mathrm{~kg} / \mathrm{m}^{2}$. Over half the patients presented with STEMI (61.5\%) as the index ACS event (Table 1).

Among the reported CV risk factors and comorbidities at baseline, most patients had dyslipidemia (77.8\%). Other atherosclerotic risk factors were medical history of hypertension (73.4\%)

\section{Advance Publication Journal of Atherosclerosis and Thrombosis}


Table 2. LLT at the time of and post ACS

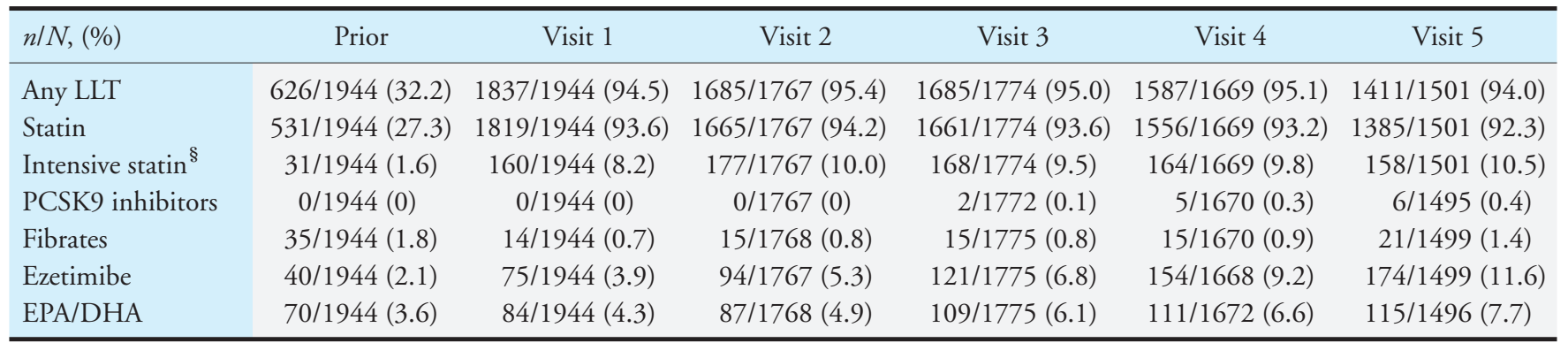

${ }^{\S}$ Defined as atorvastatin $20 \mathrm{mg}$, rosuvastatin $\geq 10 \mathrm{mg}$, or pitavastatin $4 \mathrm{mg}$

ACS, acute coronary syndrome; DHA, docosahexaenoic acid; EPA, eicosapentaenoic acid; LLT, lipid-lowering therapy; PCSK9, proprotein convertase subtilisin/kexin type 9 .

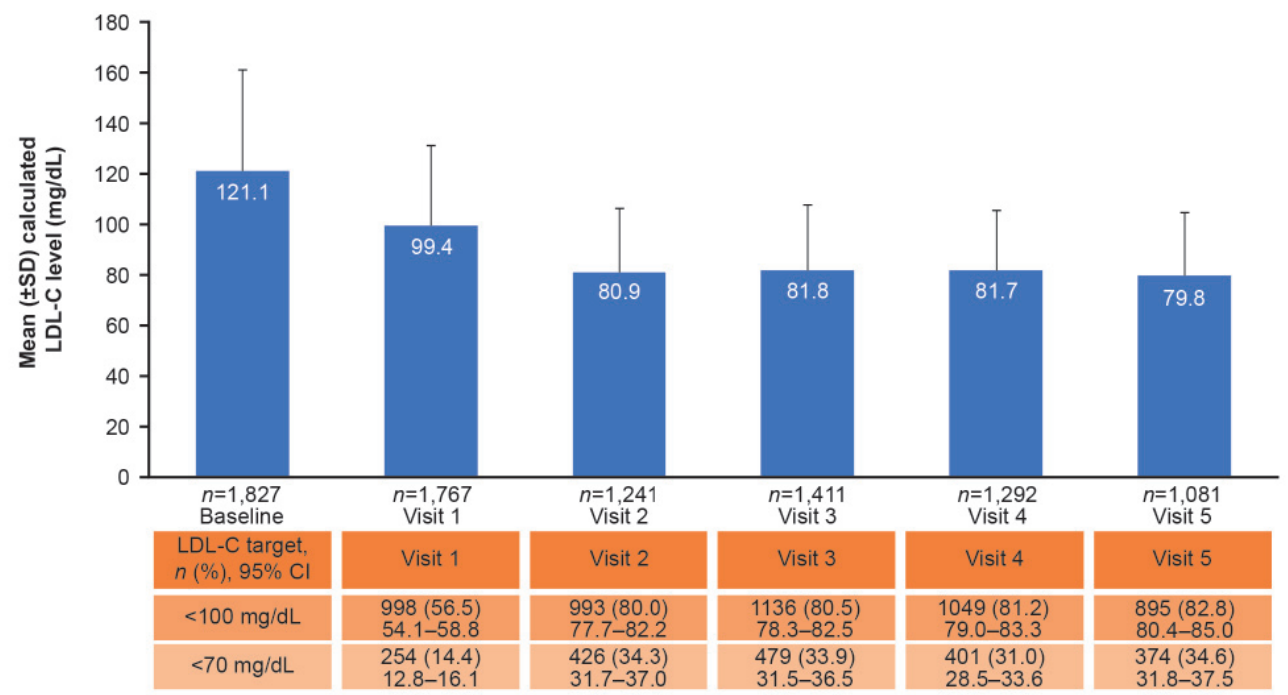

Fig. 2. Mean $( \pm S D)$ LDL-C levels over 2 years of follow-up, plus the proportions of patients achieving LDL-C target levels CI, confidence interval; LDL-C, low-density lipoprotein cholesterol; SD, standard deviation.

or diabetes mellitus (34.9\%), and current smoker $(38.0 \%)$ or history of smoking $(27.8 \%)$; a number of patients also had a previous history of CAD, CVA, dialysis, and/or $\mathrm{PAD}^{19)}$.

\section{Lipid Management Post ACS}

Overall, one-third of patients were on an LLT prior to hospitalization for ACS (32.2\%), predominantly statin therapy $(27.3 \%)$; among patients taking any LLT, the proportion on statin therapy was $84.8 \%$. Following hospitalization for ACS, at Visit 1 $94.5 \%$ of patients were on an LLT, including statin therapy, intensive statin therapy, and ezetimibe, which were prescribed for $93.6 \%, 8.2 \%$ and $3.9 \%$ of patients, respectively; at Visit 5 this was $92.3 \%$, $10.5 \%$, and $11.6 \%$ of patients, respectively (Table 2 ). No patients received PCSK9 inhibitors at Visit 1, and at Visit 5 six patients $(0.4 \%)$ had received this LLT.
Lipid Profile up to 2 Years Post ACS

Mean baseline LDL-C was $121.3 \mathrm{mg} / \mathrm{dL}$; other lipid/lipoprotein baseline levels are shown in Table 1 . Mean LDL-C level improved from the first measurement post ACS to Visit $1(99.4 \mathrm{mg} / \mathrm{dL})$ and V2 $(80.9 \mathrm{mg} / \mathrm{dL})$, and remained stable up to Visit 5 (79.8 $\mathrm{mg} / \mathrm{dL}$; Fig. 2). Similarly, the proportion of patients achieving an LDL-C level $<70 \mathrm{mg} / \mathrm{dL}$ and $<100 \mathrm{mg} / \mathrm{dL}$ increased from Visit $1(14.4 \%$ and $56.5 \%$, respectively) to Visit $2(34.3 \%$ and $80.0 \%$, respectively), and remained constant up to Visit 5 (34.6\% and 82.8\%, respectively; Fig. 2 ).

Mean total cholesterol, HDL-C, and nonHDL-C were also improved in a similar manner, with the greatest changes being observed from Visits 1 to 2 and achieved levels remaining stable from Visits 2 to 5 (Fig. 3). 
(A)

(C)
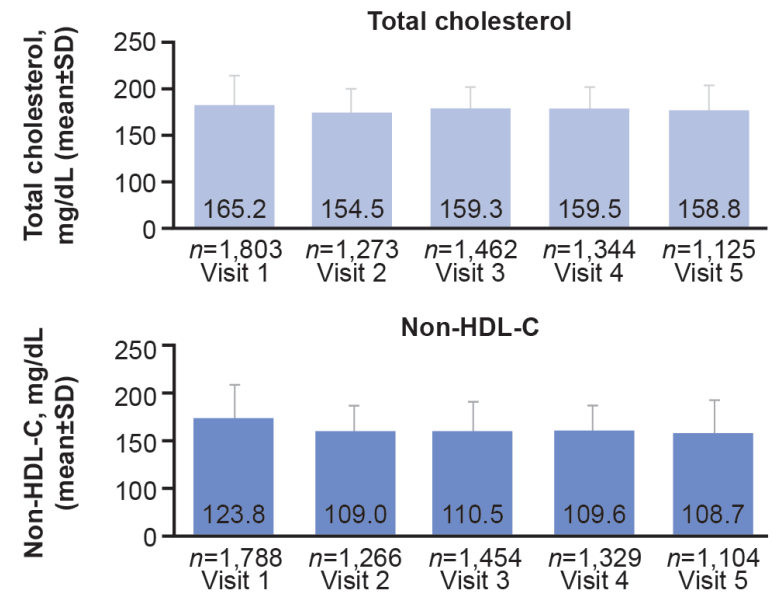

(B)

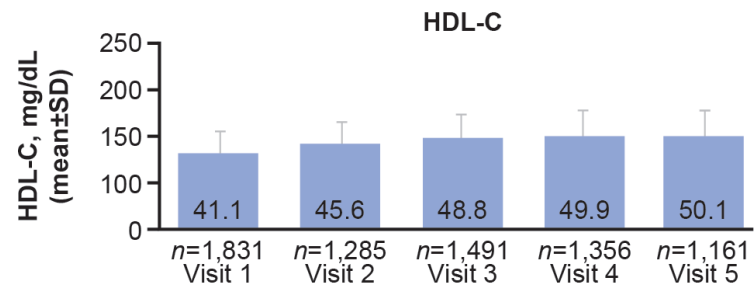

(D)

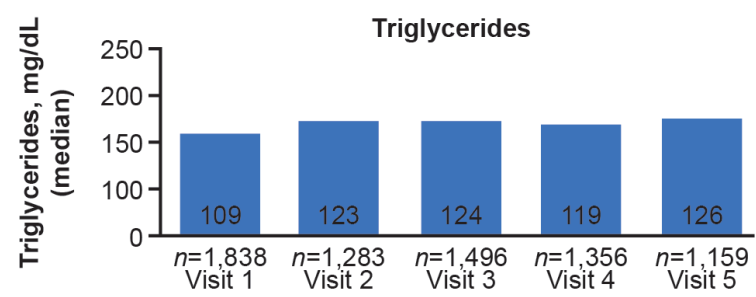

Fig. 3. Mean \pm SD lipid/lipoprotein levels over 2 years of follow-up

LDL-C, low-density lipoprotein cholesterol; HDL-C, high-density lipoprotein cholesterol; SD, standard deviation.

Table 3. Incidence of first MACE in post-ACS patients $(N=1,944)$

\begin{tabular}{lcc}
\hline & MACE up to Day 730, $n(\%)$ & Total number of events \\
\hline Overall MACE & $120(6.2)$ & 133 \\
Death associated with MI/CVA, and other CV death & $13(0.7)$ & 13 \\
MI & $4(0.2)$ & 4 \\
Other CV deaths & $2(0.1)$ & 2 \\
CVA & $7(0.4)$ & 7 \\
Nonfatal ACS requiring hospitalization & $80(4.1)$ & 85 \\
Nonfatal CVA requiring hospitalization & $30(1.5)$ & 35 \\
\hline
\end{tabular}

MACE were defined as death associated with MI/CVA or other CV death, non-fatal ACS (MI or hospitalization for UA]), and non-fatal CVA requiring hospitalization during the observation period.

ACS, acute coronary syndrome; CV, cardiovascular; CVA, cerebrovascular accident; MACE, major adverse cardiovascular events; MI, myocardial infarction; UA, unstable angina.

\section{Incidence of MACE Post ACS}

Over 2 years post ACS, the incidence of MACE was $6.2 \%(120 / 1944)$ and 133 events were reported (Table 3). There were $13 \mathrm{CV}$-related deaths, and the numbers of hospitalizations for ACS and CVA were 85 and 35, respectively. Overall, the incidence of any outcome event over 2 years post ACS was 14.7\% $(n=285 ; 364$ events). The most frequent events were coronary revascularization based on myocardial ischemia, inpatient treatment due to the occurrence or exacerbation of heart failure, and non-coronary revascularization, which occurred in $11.3 \%(n=219$; 250 events), $3.0 \%$ ( $n=59 ; 79$ events), and $1.2 \%$ ( $n=23 ; 28$ events) of all patients, respectively. Other events reported were acute arterial obstruction $0.2 \%$ ( $n=4$; four events), TIA $0.1 \%(n=1$, one event), and other adverse events prolonging or requiring hospitalization $0.1 \%(n=2$, two events).
At 2-year follow up, the cumulative incidence of MACE was 6.8\% (95\% CI: 5.7-8.1\%; Kaplan-Meier analysis; Fig.4). The cumulative incidence of CV death was $0.7 \%(95 \% \mathrm{CI}: 0.4-1.3 \%)$, and that of non-fatal ACS and CVA was 4.5\% (95\% CI: 3.7$5.6 \%)$ and $1.7 \%$ (95\% CI: $1.2-2.5 \%)$, respectively.

\section{LDL-C Reduction and Incidence of MACE Post ACS}

In subgroup analysis by baseline LDL-C, the probability of MACE was higher for patients with baseline LDL-C $<70 \mathrm{mg} / \mathrm{dL}$ compared with those with LDL-C $\geq 70 \mathrm{mg} / \mathrm{dL}$ (log-rank test $P=0.004$; Supplementary Fig. 2). The significance did not remain when adjusted for risk factors (age, PAD, diabetes mellitus, glomerular filtration rate, hemoglobin, and previous history of CAD; $P=0.6869)$. No significant difference in the

\section{Advance Publication Journal of Atherosclerosis and Thrombosis}




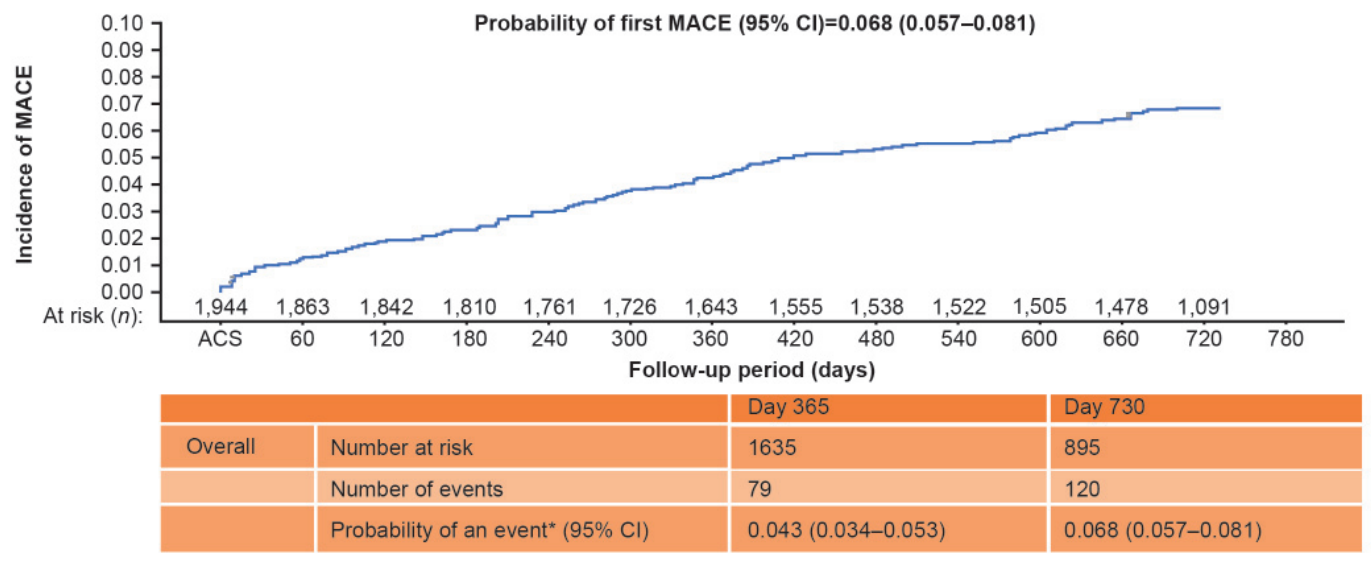

Fig. 4. Kaplan-Meier curve for the incidence of MACE over 2 years of follow-up

*Kaplan-Meier estimates.

ACS occurrence day was defined as Day 1.

ACS, acute coronary syndrome; CI, confidence interval; MACE, major adverse cardiovascular events.

probability of an event was seen between subgroups with baseline LDL-C $<100$ versus $\geq 100 \mathrm{mg} / \mathrm{dL}$ (logrank test $P=0.467$ ).

Subgroup analysis by quartiles of change (Fig. 5) showed that patients with a greater LDL-C reduction by Visit 1 had a lower probability of MACE, suggesting that an early reduction in LDL-C levels was beneficial in patients following ACS (Fig. 5A). Similarly, patients with a sustained reduction in their LDL-C level by Visit 3 had a lower probability of events (Fig. 5C). Patient baseline characteristics varied by quartiles of absolute and percent LDL-C change from first measurement to Visit 1 (Supplementary Tables 1 and 2) and first measurement to Visit 3 (Supplementary Tables 3 and 4), such as age, BMI, type of ACS, lipid levels, and smoking status. The higher the baseline LDL-C, the greater the absolute and percent reduction in LDL-C; however, there was marked difference in incidence of MACE even if there was no significant difference in the achieved LDL-C level.

\section{Discussion}

This analysis of data from the EXPLORE-J registry showed that lipid management in post-ACS patients in Japan is suboptimal, resulting in an unfavorable $\mathrm{CV}$ event rate in current clinical practice. Although most patients $(94.5 \%)$ received LLT following hospitalization for ACS, despite the highrisk status of the study population, a very limited proportion received intensive statin therapy or ezetimibe $(8.2 \%$ and $3.9 \%$, respectively). At 2-year follow-up, the proportion was only marginally greater $(10.5 \%$ and $11.6 \%)$, while $65.4 \%$ of patients had inadequately controlled LDL-C levels of $\geq 70 \mathrm{mg} / \mathrm{dL}$ at this time.

At 2 years post ACS, the incidence of MACE in this analysis was $6.2 \%$, which is similar to the 2-year incidence of MACE (6.4\%) in Japanese patients with ACS in the PACIFIC registry ${ }^{20,21)}$. Notably, the incidence of MACE was lower among patients with greater absolute LDL-C reduction in our analysis. Randomized controlled trials of LLTs have demonstrated a positive association between further LDL-C lowering, even to below the current recommended targets, and reduced $\mathrm{CV}$ events ${ }^{7-11,23)}$; however, our results need to be interpreted carefully. Baseline LDL-C levels, not treated LDL-C levels, were used in our analysis. Notably, for patients with baseline LDL-C $<70 \mathrm{mg} / \mathrm{dL}$ there was no significant reduction in the risk of MACE. This result may indicate that there is some difficulty in targeting LDL-C levels with LLT. Several further explanations could be proposed. One is that lower baseline LDL-C levels can reflect factors of an unfavorable prognosis such as poor nutrition, frailty, advanced age, and other comorbidities such as heart failure. Patient data regarding heart failure, ejection failure, and albumin levels would clarify findings; however, this data was not available and further investigation is required. It may be that lower LDL-C at baseline was related to a larger LDL-C reduction due to a larger infarct size, hence a higher MACE incidence can be explained by a more severe event. The event rate is a likely reflection of background high-risk characteristics rather than the prognostic reflection of LDL-C levels. Another explanation is that this population may be undertreated with non-LDL-C-lowering therapies for $\mathrm{CV}$ risk reduction because of their low baseline 

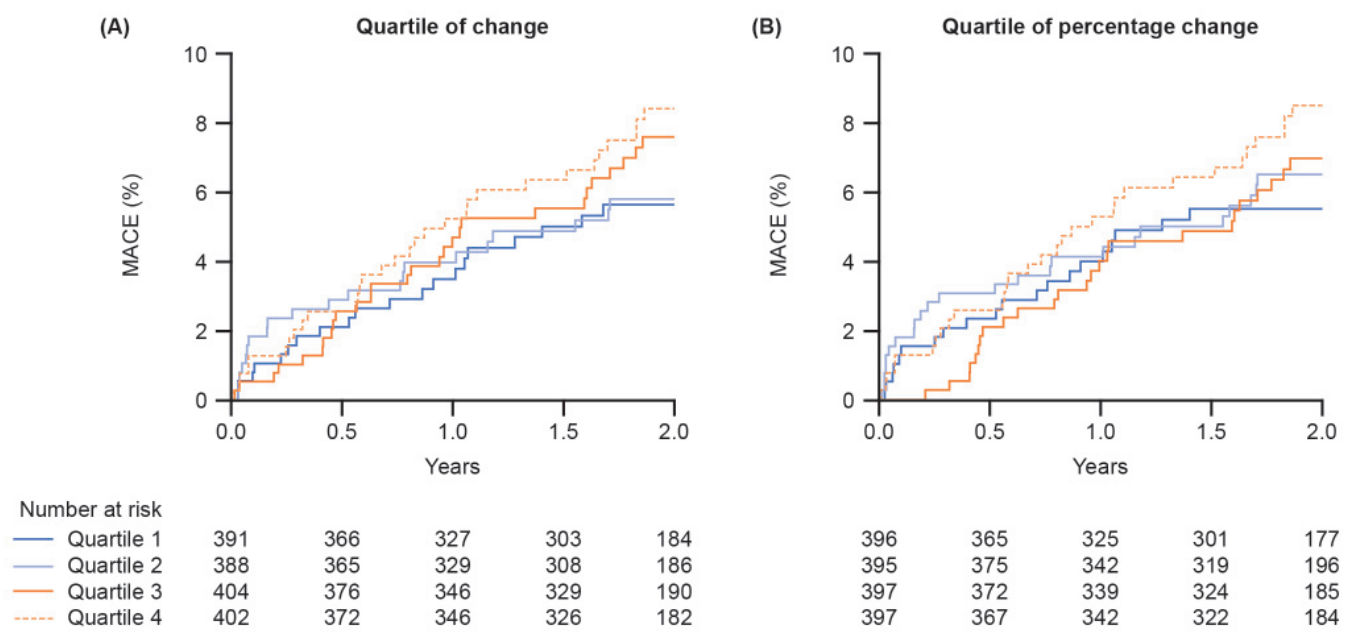

(C)

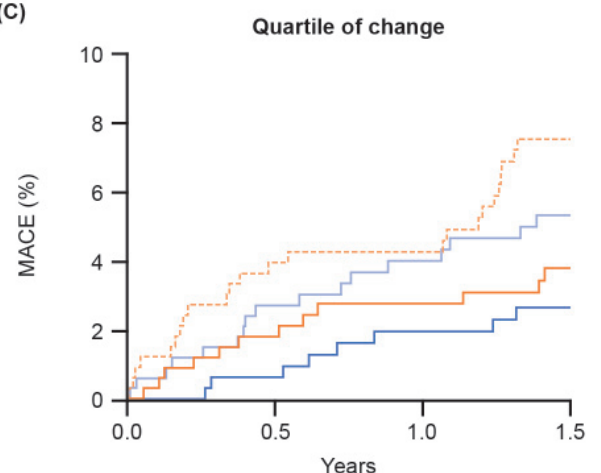

(D)

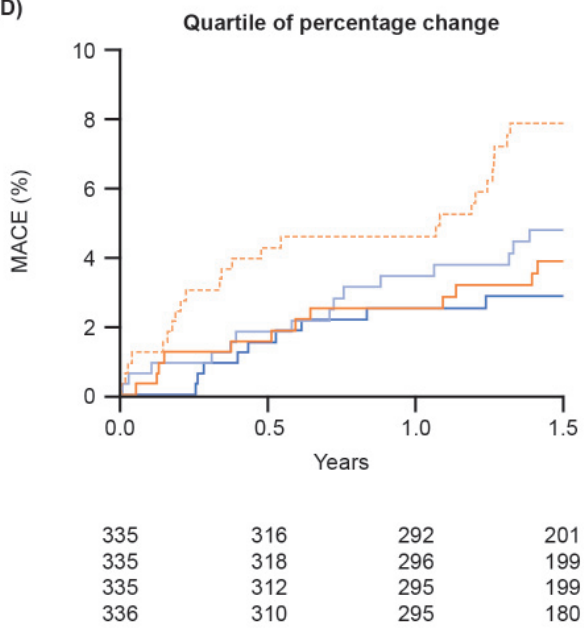

Fig. 5. Probability of first MACE in subgroups by quartile of absolute LDL-C reduction and by quartile of percentage change in LDL-C from first measurement after hospitalization to (A and B) Visit 1 and (C and D) Visit 3

Visit 1 was within 14 days of hospitalization for ACS.

LDL-C, low-density lipoprotein cholesterol; MACE, major adverse cardiovascular events.

\section{LDL-C levels.}

In post-ACS patients, early ${ }^{24)}$ and sustained ${ }^{11)}$ reductions in LDL-C levels are beneficial. Most recently, the ESC/EAS updated their guidelines for the management of dyslipidemias. The 2019 update recommends even lower LDL-C levels $(<55 \mathrm{mg} / \mathrm{dL})$ in very high-risk patients including those with ACS, largely based on the results from the Evaluation of Cardiovascular Outcomes After an Acute Coronary Syndrome During Treatment With Alirocumab (ODYSSEY OUTCOMES) trial in 18,924 patients with recent ACS (within 1-12 months) ${ }^{11)}$. The target LDL-C in this trial was $25-50 \mathrm{mg} / \mathrm{dL}$. The ESC/EAS guidelines also recommend reducing LDL-C levels by $50 \%$ from baseline; in ODYSSEY OUTCOMES LDL-C reductions of $>50 \%$ were observed early with PCSK9 inhibitor therapy (alirocumab) and were generally sustained during a median 2.8 years of follow-up, reducing the risk of $\mathrm{MACE}^{11)}$ and $\mathrm{CV}$ mortality ${ }^{25)}$. In our study, subgroup analysis showed that patients with a greater early (by Visit 1) LDL-C reduction had a lower probability of MACE; this was also seen for patients whose LDL-C reduction was maintained at Visit 3. Additionally, a greater reduction in LDL-C levels is associated with better outcomes at early and late stages. This supports the need for intensification of LLT, with initial intensification of statin therapy to maximal tolerated dose, as suggested in the 2019 Japanese Circulation Society (JCS) guidelines for Japanese patients ${ }^{4)}$.

The 2012 JAS guidelines for the prevention of ASCVD $^{15)}$, recommending an LDL-C target of $<100 \mathrm{mg} / \mathrm{dL}$

\section{Advance Publication Journal of Atherosclerosis and Thrombosis}


for secondary prevention in high-risk patients with established CAD, were revised in $2017^{26)}$ (during the follow-up period of our study) to a lower target of $<$ $70 \mathrm{mg} / \mathrm{dL}$. The 2019 JCS guidelines reinforced intensive LDL-C lowering and recommended a maximum tolerated dose of intensive statin therapy for all post-ACS patients ${ }^{4)}$. Nevertheless, our study results show that, in a real-life clinical practice setting in Japan, more than half of post-ACS LLT-treated patients were not at guideline-recommended LDL-C target at 2 years post ACS, and the use of highintensity statins and ezetimibe was very low despite the suboptimal LDL-C target achievement. The lack of alignment with guideline revisions may reflect the difficulty in achieving a 'treat-to-target' strategy, which in general has a tendency to lead to inadequate treatment and can be an obstacle in daily clinical work. In our study, LLT titration to achieve target LDL-C levels was suboptimal. This may have been due to concerns regarding adverse events associated with the use of higher-dose statins, and/or lack of awareness regarding urgency to treat. In fact, patients in the fourth quartile of LDL-C change had lower baseline LDL-C and BMI than patients in the other quartiles, suggesting that baseline LDL-C is one of the key determinants in drug titration decisions. Emerging evidence and new guidelines support the implementation of more aggressive residual risk management with higher dose statin therapy followed by PCSK9 inhibitors (which are associated with a very favorable safety profile), with or without ezetimibe, to achieve target LDL-C and CV event reduction according to patients' baseline risk.

It cannot be discounted that the higher $\mathrm{CV}$ event rate seen in our study in patients with residual elevated LDL-C may be attributed in part to confounding factors such as heart failure, or an individual's muscle mass or nutritional state. Further limitations of this analysis include the observational nature of the study that the data was accessed from, the small sample size and number of events, the fact that the subanalyses did not have formal power calculations, and the study duration (2 years).

\section{Conclusion}

Lipid management in post-ACS patients in Japan is suboptimal, and patients remain at considerable risk of recurrent ischemic events. Intensification of LDL-C management with greater use of high-intensity statin therapy, and use of additional LLT with ezetimibe and/or a PCSK9 inhibitor, is needed to reduce the risk of CV morbidity and mortality in high-risk patients in Japan, including those with ACS. To further characterize and quantify the patient population and the benefit from lipid management, an additional analysis of EXPLORE-J by risk stratification of the patient population is planned.

\section{Acknowledgements}

The authors thank the patients, their families, and all investigators involved in the study; Tamio Teramoto of Teikyo University (Tokyo, Japan), Shun Ishibashi of Jichi Medical University (Tochigi, Japan), Kotaro Yokote of Chiba University (Chiba, Japan), Tomonori Okamura of Keio University (Tokyo, Japan), and Hiroyuki Daida of Juntendo University (Tokyo, Japan) for collaboration and advice regarding planning of the study; Mebix (Tokyo, Japan) for assistance with study implementation/operation; BML (Tokyo, Japan) for PCSK9-related and genome-related analysis; CTD (Tokyo, Japan) for consulting; and Shizuya Yamashita of Rinku General Medical Center (Osaka, Japan) and Toru Yoshizumi of Kawasaki Hospital (Hyogo, Japan) for advice on aspects of methodology. The authors would also like to thank Yoshiharu Takagi and Yukiko Morimoto of Sanofi for providing support with statistical analysis; and Yasunori Nakahigashi and Makiko Usami of Sanofi for assistance with study implementation/operation. Medical writing assistance and editorial support, under the direction of the authors, were provided by Nila Bhana, MSc, of Prime Global (Knutsford, United Kingdom) according to Good Publication Practice guidelines (http://annals.org/aim/article/2424869/ good-publication-practice-communicating-companysponsored-medical-research-gpp3) and funded by Sanofi. The authors were involved in the study design as well as the collection, analysis, and interpretation of data. All authors had full access to all the data in this study and take complete responsibility for the integrity of the data and accuracy of the data analysis.

\section{Sources of Funding}

This study was funded by Sanofi and Regeneron Pharmaceuticals, Inc.

\section{Disclosures}

Masato Nakamura and Junya Ako have received honoraria from Daiichi Sankyo, Kowa, Bayer, Amgen Astellas Biopharma, and Sanofi.

Hidenori Arai has received honoraria from Sanofi, Daiichi Sankyo, MSD, Kowa, and Pfizer.

Atsushi Hirayama has received honoraria from Bayer, Daiichi Sankyo, Astellas Amgen Biopharma, 
Astellas, Sanofi, MSD, and Eisai; clinical research funding from Bayer and Daiichi Sankyo; and scholarship grants from MSD, Sanofi, Astellas Amgen Biopharma, and Daiichi Sankyo.

Atsushi Nohara has received honoraria from Sanofi.

Yoshitaka Murakami has no conflicts of interest to declare.

Asuka Ozaki is an employee of Sanofi.

Mariko Harada-Shiba has received honoraria from Amgen Astellas Biopharma, Astellas, Sanofi, MSD, Kowa, and Aegerion; and scholarship grants from Aegerion, Astellas, Kaneka Medics, Takeda, and Recordati.

\section{References}

1) Davis KL, Meyers J, Zhao Z, McCollam PL and Murakami M: High-Risk Atherosclerotic Cardiovascular Disease in a Real-World Employed Japanese Population: Prevalence, Cardiovascular Event Rates, and Costs. J Atheroscler Thromb, 2015; 22: 1287-1304

2) Hata J, Ninomiya T, Hirakawa Y, Nagata M, Mukai N, Gotoh S, Fukuhara M, Ikeda F, Shikata K, Yoshida D, Yonemoto K, Kamouchi M, Kitazono T and Kiyohara Y: Secular trends in cardiovascular disease and its risk factors in Japanese: half-century data from the Hisayama Study (1961-2009). Circulation, 2013; 128: 1198-1205

3) Grundy SM, Stone NJ, Bailey AL, Beam C, Birtcher KK, Blumenthal RS, Braun LT, de Ferranti S, FaiellaTommasino J, Forman DE, Goldberg R, Heidenreich PA, Hlatky MA, Jones DW, Lloyd-Jones D, Lopez-Pajares N, Ndumele CE, Orringer CE, Peralta CA, Saseen JJ, Smith SC, Jr., Sperling L, Virani SS and Yeboah J: 2018 AHA/ ACC/AACVPR/AAPA/ABC/ACPM/ADA/AGS/APhA/ ASPC/NLA/PCNA Guideline on the Management of Blood Cholesterol: Executive Summary: A Report of the American College of Cardiology/American Heart Association Task Force on Clinical Practice Guidelines. J Am Coll Cardiol, 2019; 73: 3168-3209

4) Kimura K, Kimura T, Ishihara M, Nakagawa Y, Nakao K, Miyauchi K, Sakamoto T, Tsujita K, Hagiwara N, Miyazaki S, Ako J, Arai H, Ishii H, Origuchi H, Shimizu W, Takemura H, Tahara Y, Morino Y, Iino K, Itoh T, Iwanaga Y, Uchida K, Endo H, Kongoji K, Sakamoto K, Shiomi H, Shimohama T, Suzuki A, Takahashi J, Takeuchi I, Tanaka A, Tamura T, Nakashima T, Noguchi T, Fukamachi D, Mizuno T, Yamaguchi J, Yodogawa K, Kosuge M, Kohsaka S, Yoshino H, Yasuda S, Shimokawa H, Hirayama A, Akasaka T, Haze K, Ogawa H, Tsutsui H and Yamazaki T: JCS 2018 Guideline on Diagnosis and Treatment of Acute Coronary Syndrome. Circ J, 2019; 83: 1085-1196

5) Catapano AL, Graham I, De Backer G, Wiklund O, Chapman MJ, Drexel H, Hoes AW, Jennings CS, Landmesser U, Pedersen TR, Reiner Z, Riccardi G, Taskinen MR, Tokgozoglu L, Verschuren WMM, Vlachopoulos C, Wood DA, Zamorano JL, Cooney MT and ESC Scientific Document Group: 2016 ESC/EAS guidelines for the management of dyslipidaemias. Eur Heart J, 2016; 37: 2999-3058

6) Rossini R, Capodanno D, Lettieri C, Musumeci G, Limbruno U, Molfese M, Spatari V, Calabria P, Romano M, Tarantini G, Gavazzi A and Angiolillo DJ: Long-term outcomes of patients with acute coronary syndrome and nonobstructive coronary artery disease. Am J Cardiol, 2013; 112: 150-155

7) Silverman MG, Ference BA, Im K, Wiviott SD, Giugliano RP, Grundy SM, Braunwald E and Sabatine MS: Association Between Lowering LDL-C and Cardiovascular Risk Reduction Among Different Therapeutic Interventions: A Systematic Review and Meta-analysis. JAMA, 2016; 316: 1289-1297

8) Cholesterol Treatment Trialists Collaboration, Baigent C, Blackwell L, Emberson J, Holland LE, Reith C, Bhala N, Peto R, Barnes EH, Keech A, Simes J and Collins R: Efficacy and safety of more intensive lowering of LDL cholesterol: a meta-analysis of data from 170,000 participants in 26 randomised trials. Lancet, 2010; 376: 1670-1681

9) Cannon CP, Blazing MA, Giugliano RP, McCagg A, White JA, Theroux P, Darius H, Lewis BS, Ophuis TO, Jukema JW, De Ferrari GM, Ruzyllo W, De Lucca P, Im K, Bohula EA, Reist C, Wiviott SD, Tershakovec AM, Musliner TA, Braunwald E, Califf RM and IMPROVE-IT Investigators: Ezetimibe added to statin therapy after acute coronary syndromes. N Engl J Med, 2015; 372: 2387-2397

10) Sabatine MS, Giugliano RP, Keech AC, Honarpour N, Wiviott SD, Murphy SA, Kuder JF, Wang H, Liu T, Wasserman SM, Sever PS, Pedersen TR and Fourier Steering Committee Investigators: Evolocumab and clinical outcomes in patients with cardiovascular disease. N Engl J Med, 2017; 376: 1713-1722

11) Schwartz GG, Steg PG, Szarek M, Bhatt DL, Bittner VA, Diaz R, Edelberg JM, Goodman SG, Hanotin C, Harrington RA, Jukema JW, Lecorps G, Mahaffey KW, Moryusef A, Pordy R, Quintero K, Roe MT, Sasiela WJ, Tamby JF, Tricoci P, White HD, Zeiher AM and ODYSSEY OUTCOMES Committees Investigators: Alirocumab and cardiovascular outcomes after acute coronary syndrome. N Engl J Med, 2018; 379: $2097-$ 2107

12) Okazaki S, Yokoyama T, Miyauchi K, Shimada K, Kurata T, Sato $\mathrm{H}$ and Daida $\mathrm{H}$ : Early statin treatment in patients with acute coronary syndrome: demonstration of the beneficial effect on atherosclerotic lesions by serial volumetric intravascular ultrasound analysis during half a year after coronary event: the ESTABLISH Study. Circulation, 2004; 110: 1061-1068

13) Dohi T, Miyauchi K, Okazaki S, Yokoyama T, Yanagisawa N, Tamura H, Kojima T, Yokoyama K, Kurata T and Daida $\mathrm{H}$ : Early intensive statin treatment for six months improves long-term clinical outcomes in patients with acute coronary syndrome (Extended-ESTABLISH trial): a follow-up study. Atherosclerosis, 2010; 210: 497-502

14) Nakamura M, Uno K, Hirayama A, Ako J, Nohara A, Arai $\mathrm{H}$ and Harada-Shiba $\mathrm{M}$ : Exploration into lipid management and persistent risk in patients hospitalised for acute coronary syndrome in Japan (EXPLORE-J): 
protocol for a prospective observational study. BMJ Open, 2017; 7: e014427

15) Teramoto T, Sasaki J, Ishibashi S, Birou S, Daida H, Dohi S, Egusa G, Hiro T, Hirobe $K$, Iida $M$, Kihara $S$, Kinoshita M, Maruyama C, Ohta T, Okamura T, Yamashita S, Yokode M, Yokote $\mathrm{K}$ and Japan Atherosclerosis S: Executive summary of the Japan Atherosclerosis Society (JAS) guidelines for the diagnosis and prevention of atherosclerotic cardiovascular diseases in Japan -2012 version. J Atheroscler Thromb, 2013; 20: $517-523$

16) Stone NJ, Robinson J, Lichtenstein AH, Bairey Merz CN, Lloyd-Jones DM, Blum CB, McBride P, Eckel RH, Schwartz JS, Goldberg AC, Shero ST, Gordon D, Smith SC, Jr., Levy D, Watson K and Wilson PW: 2013 ACC/ AHA guideline on the treatment of blood cholesterol to reduce atherosclerotic cardiovascular risk in adults: a report of the American College of Cardiology/American Heart Association Task Force on practice guidelines. J Am Coll Cardiol, 2014; 63: 2889-2934

17) Reiner Z, Catapano AL, De Backer G, Graham I, Taskinen MR, Wiklund O, Agewall S, Alegria E, Chapman MJ, Durrington P, Erdine S, Halcox J, Hobbs RH, Kjekshus JK, Perrone Filardi P, Riccardi G, Storey RF, David W and Clinical Practice Guidelines Committee of the Spanish Society of Cardiology: [ESC/EAS Guidelines for the management of dyslipidaemias]. Rev Esp Cardiol, 2011; 64: 1168 e1161-1168 e1160

18) Harada-Shiba M, Ako J, Arai H, Hirayama A, Murakami Y, Nohara A, Ozaki A, Uno $K$ and Nakamura M: Prevalence of familial hypercholesterolemia in patients with acute coronary syndrome in Japan: Results of the EXPLORE-J study. Atherosclerosis, 2018; 277: 362-368

19) Nakamura M, Ako J, Arai H, Hirayama A, Murakami Y, Nohara A, Uno K, Ozaki A and Harada-Shiba M: Investigation into lipid management in acute coronary syndrome patients from the EXPLORE-J study. J Atheroscler Thromb, 2019; 26: 559-572

20) Miyauchi K, Morino Y, Tsukahara K, Origasa H, Daida $\mathrm{H}$ and PACIFIC Steering Committee Members: The PACIFIC (Prevention of AtherothrombotiC Incidents Following Ischemic Coronary attack) Registry: Rationale and design of a 2-year study in patients initially hospitalised with acute coronary syndrome in Japan. Cardiovasc Drugs Ther, 2010; 24: 77-83
21) Daida H, Miyauchi K, Ogawa H, Yokoi H, Matsumoto M, Kitakaze M, Kimura T, Matsubara T, Ikari Y, Kimura $\mathrm{K}$, Tsukahara $\mathrm{K}$, Origasa $\mathrm{H}$, Morino $\mathrm{Y}$, Tsutsui $\mathrm{H}$, Kobayashi $\mathrm{M}$ and Isshiki T: Management and two-year long-term clinical outcome of acute coronary syndrome in Japan: prevention of atherothrombotic incidents following ischemic coronary attack (PACIFIC) registry. Circ J, 2013; 77: 934-943

22) Friedewald WT, Levy RI and Fredrickson DS: Estimation of the concentration of low-density lipoprotein cholesterol in plasma, without use of the preparative ultracentrifuge. Clin Chem, 1972; 18: 499-502

23) Ray KK, Ginsberg HN, Davidson MH, Pordy R, Bessac L, Minini P, Eckel RH and Cannon CP: Reductions in atherogenic lipids and major cardiovascular events: A pooled analysis of 10 ODYSSEY trials comparing alirocumab with control. Circulation, 2016; 134: 19311943

24) Schwartz GG, Olsson AG, Ezekowitz MD, Ganz P, Oliver MF, Waters D, Zeiher A, Chaitman BR, Leslie S and Stern T: Effects of atorvastatin on early recurrent ischemic events in acute coronary syndromes: the MIRACL study: a randomized controlled trial. JAMA, 2001; 285: 17111718

25) Steg PG, Szarek M, Bhatt DL, Bittner VA, Bregeault MF, Dalby AJ, Diaz R, Edelberg JM, Goodman SG, Hanotin C, Harrington RA, Jukema JW, Lecorps G, Mahaffey KW, Moryusef A, Ostadal P, Parkhomenko A, Pordy R, Roe MT, Tricoci P, Vogel R, White HD, Zeiher AM and Schwartz GG: Effect of Alirocumab on Mortality After Acute Coronary Syndromes. Circulation, 2019; 140: 103112

26) Kinoshita M, Yokote K, Arai H, Iida M, Ishigaki Y, Ishibashi S, Umemoto S, Egusa G, Ohmura H, Okamura T, Kihara S, Koba S, Saito I, Shoji T, Daida $H$, Tsukamoto K, Deguchi J, Dohi S, Dobashi K, Hamaguchi $H$, Hara M, Hiro T, Biro S, Fujioka Y, Maruyama C, Miyamoto Y, Murakami Y, Yokode M, Yoshida H, Rakugi H, Wakatsuki A, Yamashita S and Committee for Epidemiology and Clinical Management of Atherosclerosis: Japan Atherosclerosis Society (JAS) Guidelines for Prevention of Atherosclerotic Cardiovascular Diseases 2017. J Atheroscler Thromb, 2018; 25: 846-984 


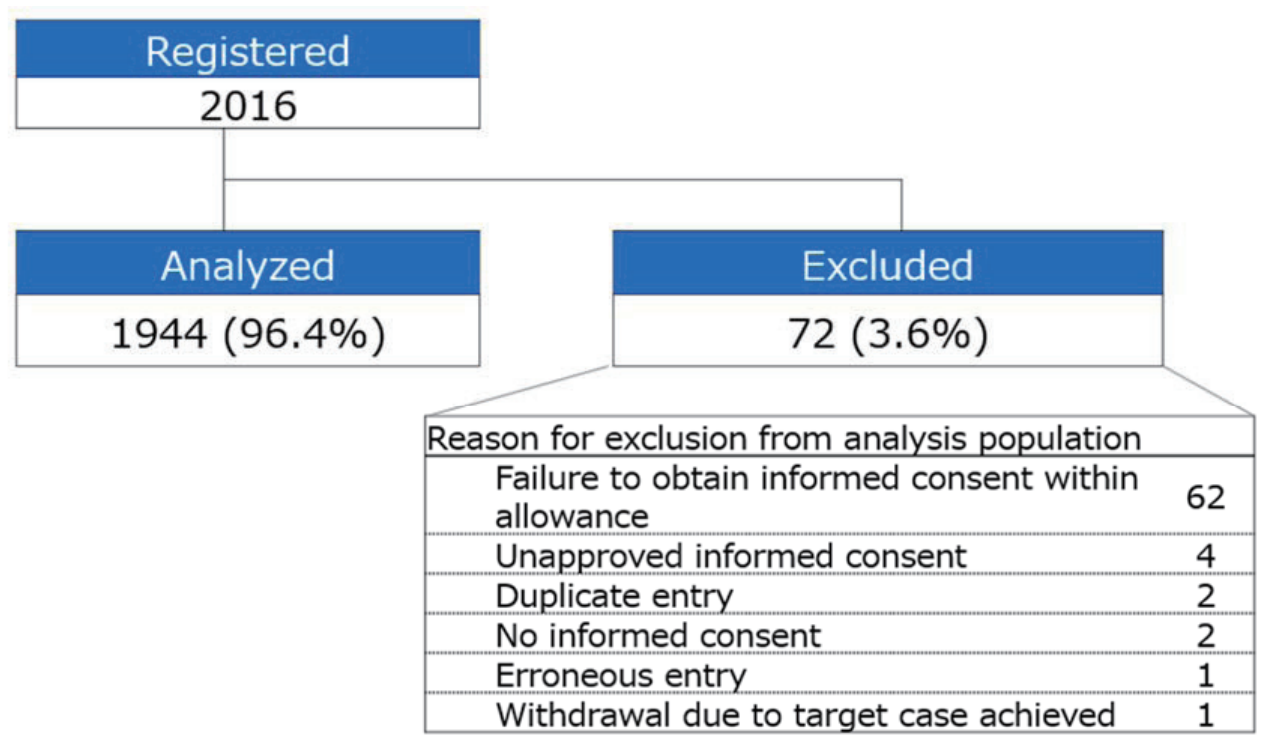

Supplementary Fig. 1. Reasons for patient exclusion

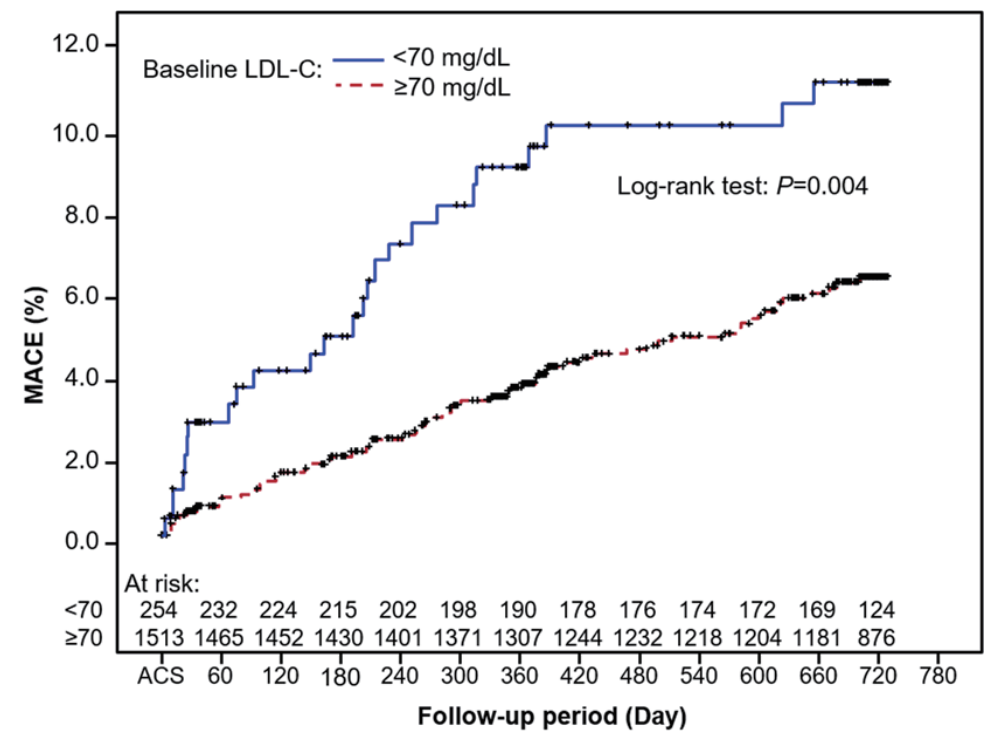

Supplementary Fig.2. Kaplan-Meier cumulative incidence curve for time to first MACE by subgroup, baseline LDL-C $<70$ or $\geq 70 \mathrm{mg} / \mathrm{dL}$

Day is based on ACS occurrence date (Day 1)

ACS, acute coronary syndrome; LDL-C, low-density lipoprotein cholesterol; MACE, major adverse cardiovascular event. 
Supplementary Table 1. Patient baseline characteristics and lipid profiles, and LLT post ACS and change in LDL-C: subgroup analysis by quartile of absolute LDL-C change from the first measurement after hospitalization to Visit $1^{\S}$

\begin{tabular}{|c|c|c|c|c|c|c|}
\hline & $\begin{array}{l}\text { All patients } \\
(n=1,585)\end{array}$ & $\begin{array}{c}\mathrm{Q} 1 \\
(n=391)\end{array}$ & $\begin{array}{c}\mathrm{Q} 2 \\
(n=388)\end{array}$ & $\begin{array}{c}\mathrm{Q} 3 \\
(n=404)\end{array}$ & $\begin{array}{c}\mathrm{Q} 4 \\
(n=402)\end{array}$ & $P$-value \\
\hline Age, years, mean (SD) & $66.2(12.2)$ & $63.7(12.4)$ & $65.8(12.0)$ & $67.0(12.0)$ & $68.1(11.9)$ & $<0.001$ \\
\hline Male, $n(\%)$ & $1,268(80.0)$ & $306(78.3)$ & $315(81.2)$ & $324(80.2)$ & $323(80.3)$ & 0.772 \\
\hline BMI, $\mathrm{kg} / \mathrm{m}^{2}$, mean $(\mathrm{SD})$ & $24.2(3.5)$ & $24.5(3.4)$ & $24.2(3.4)$ & $24.4(3.5)$ & $23.6(3.8)$ & $<0.001$ \\
\hline ACS type, $n(\%)$ & & & & & & $<0.001$ \\
\hline STEMI & $992(62.6)$ & $277(70.8)$ & $246(63.4)$ & $246(60.9)$ & $223(55.5)$ & \\
\hline UA & $347(21.9)$ & $49(12.5)$ & $79(20.4)$ & $114(28.2)$ & $105(26.1)$ & \\
\hline Non-STEMI & $246(15.5)$ & $65(16.6)$ & $63(16.2)$ & $44(10.9)$ & $74(18.4)$ & \\
\hline eGFR $<15 \mathrm{~mL} / \mathrm{min} / 1.73 \mathrm{~m}^{2}, n(\%)$ & $27(1.7)$ & $2(0.5)$ & $5(1.3)$ & $10(2.5)$ & $10(2.5)$ & 0.818 \\
\hline LDL-C, mean (SD), mg/dL, first measurement ${ }^{*}$ & $122.6(39.5)$ & $157.8(35.6)$ & $125.9(27.2)$ & $108.9(31.3)$ & $99.0(35.4)$ & $<0.001$ \\
\hline \multicolumn{7}{|l|}{ Baseline lipid profile (Visit 1 ), mg/dL } \\
\hline LDL-C, mean (SD), calculated & $98.9(31.4)$ & $93.6(28.4)$ & $94.2(26.2)$ & $98.4(30.9)$ & $109.1(36.4)$ & $<0.001$ \\
\hline HDL-C, mean (SD) & $40.8(11.6)$ & $38.8(11.5)$ & $40.4(10.9)$ & $41.1(11.2)$ & $42.8(12.4)$ & $<0.001$ \\
\hline Triglycerides, median (min, max) & $109(22,361)$ & $113(31,340)$ & ) $107(31,361)$ & $113(38,358)$ & $104(22,340)$ & 0.001 \\
\hline Total cholesterol, mean (SD) & $163.6(37.0)$ & $157.2(34.2)$ & $158.0(31.6)$ & $164.1(37.1)$ & $174.5(41.6)$ & $<0.001$ \\
\hline \multicolumn{7}{|l|}{ History of CV risk factors/comorbidities, $n$ (\%) } \\
\hline Dyslipidemia & $1,240(78.2)$ & $326(83.4)$ & $283(72.9)$ & $321(79.5)$ & $310(77.1)$ & 0.004 \\
\hline Hypertension & $1,154(72.8)$ & $274(70.1)$ & $267(68.8)$ & $319(79.0)$ & $294(73.1)$ & 0.006 \\
\hline Diabetes mellitus & $552(34.8)$ & $126(32.2)$ & $139(35.8)$ & $143(35.4)$ & $144(35.8)$ & 0.666 \\
\hline Smoking & & & & & & 0.002 \\
\hline Current smoker & $610(38.5)$ & $163(41.7)$ & $163(42.0)$ & $146(36.1)$ & $138(34.3)$ & \\
\hline Previous smoker & $452(28.5)$ & $104(26.6)$ & $127(32.7)$ & $116(28.7)$ & $105(26.1)$ & \\
\hline None & $523(33.0)$ & $124(31.7)$ & $98(25.3)$ & $142(35.1)$ & $159(39.6)$ & \\
\hline Coronary artery disease & $281(17.7)$ & $35(9.0)$ & $45(11.6)$ & $88(21.8)$ & $113(28.1)$ & \\
\hline Cerebrovascular accident & $126(7.9)$ & $30(7.7)$ & $23(5.9)$ & $40(9.9)$ & $33(8.2)$ & \\
\hline Dialysis & $24(1.5)$ & $1(0.3)$ & $3(0.8)$ & $10(2.5)$ & $10(2.5)$ & \\
\hline Peripheral artery disease & $29(1.8)$ & $6(1.5)$ & $8(2.1)$ & $6(1.5)$ & $9(2.2)$ & \\
\hline \multicolumn{7}{|l|}{ LLT at Visit $1, n(\%)$} \\
\hline Statin & & $380(97.2)$ & $372(95.9)$ & $376(93.1)$ & $359(89.3)$ & \\
\hline Intensive statin & & $47(12.0)$ & $24(6.2)$ & $23(5.7)$ & $27(6.7)$ & \\
\hline Ezetimibe & & $21(5.4)$ & $11(2.8)$ & $14(3.5)$ & $16(4.0)$ & \\
\hline \multicolumn{7}{|c|}{$\begin{array}{l}\text { Change in LDL-C from first measurement after } \\
\text { hospitalization to Visit } 1\end{array}$} \\
\hline Number & & 391 & 388 & 404 & 402 & \\
\hline $\mathrm{mg} / \mathrm{dL}$, mean $(\mathrm{SD})$ & & $-64.2(21.5)$ & $-31.7(6.5)$ & $-10.5(5.3)$ & $10.1(16.1)$ & \\
\hline
\end{tabular}

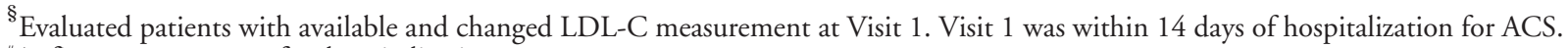

${ }^{\#}$ At first measurement after hospitalization.

ACS, acute coronary syndrome; BMI, body mass index; CV, cardiovascular; eGFR, estimated glomerular filtration rate; HDL-C, high-density lipoprotein cholesterol; LDL-C, low-density lipoprotein cholesterol; LLT, lipid-lowering therapy; SD, standard deviation; STEMI, ST-segmentelevation myocardial infarction; UA, unstable angina. 
Supplementary Table 2. Patient baseline characteristics and lipid profiles, and LLT post ACS and change in LDL-C: subgroup analysis by quartile of percent LDL-C change from the first measurement after hospitalization to Visit $1^{8}$

\begin{tabular}{|c|c|c|c|c|c|c|}
\hline & $\begin{array}{l}\text { All patients } \\
(n=1,585)\end{array}$ & $\begin{array}{c}\mathrm{Q} 1 \\
(n=391)\end{array}$ & $\begin{array}{c}\mathrm{Q} 2 \\
(n=388)\end{array}$ & $\begin{array}{c}\text { Q3 } \\
(n=404)\end{array}$ & $\begin{array}{c}\mathrm{Q} 4 \\
(n=402)\end{array}$ & $P$-value \\
\hline Age, years, mean (SD) & $66.2(12.2)$ & $65.2(12.1)$ & $65.2(12.5)$ & $66.4(12.0)$ & $67.9(11.8)$ & 0.003 \\
\hline Male, $n(\%)$ & $1,268(80.0)$ & $310(78.3)$ & $317(80.3)$ & $324(81.6)$ & $317(79.8)$ & 0.706 \\
\hline BMI, $\mathrm{kg} / \mathrm{m}^{2}$, mean $(\mathrm{SD})$ & $24.2(3.5)$ & $24.4(3.4)$ & $24.2(3.4)$ & $24.4(3.5)$ & $23.7(3.8)$ & 0.007 \\
\hline ACS type, $n(\%)$ & & & & & & $<0.001$ \\
\hline STEMI & $992(62.6)$ & $279(70.5)$ & $252(63.8)$ & $240(60.5)$ & $221(55.7)$ & \\
\hline UA & $347(21.9)$ & $53(13.4)$ & $79(20.0)$ & $111(28.0)$ & $104(26.2)$ & \\
\hline Non-STEMI & $246(15.5)$ & $64(16.2)$ & $64(16.2)$ & $46(11.6)$ & $72(18.1)$ & \\
\hline $\mathrm{eGFR}<15 \mathrm{~mL} / \mathrm{min} / 1.73 \mathrm{~m}^{2}, n(\%)$ & $27(1.7)$ & $4(1.0)$ & $4(1.0)$ & $9(2.3)$ & $10(2.5)$ & 0.835 \\
\hline LDL-C, mean (SD), mg/dL, first measurement ${ }^{*}$ & $122.6(39.5)$ & $144.0(37.2)$ & $131.6(36.7)$ & $114.2(33.0)$ & $100.8(36.4)$ & $<0.001$ \\
\hline \multicolumn{7}{|c|}{ Baseline lipid profile (Visit 1 ), $\mathrm{mg} / \mathrm{dL}$} \\
\hline LDL-C, mean $(S D)$, calculated & $98.9(31.4)$ & $82.5(22.2)$ & $98.7(27.8)$ & $103.3(29.8)$ & $111.0(36.8)$ & $<0.001$ \\
\hline HDL-C, mean (SD) & $40.8(11.6)$ & $38.5(11.4)$ & $40.4(11.0)$ & $41.2(11.1)$ & $43.0(12.4)$ & $<0.001$ \\
\hline Triglycerides, median (min, max) & $109(22,361)$ & $109(33,340)$ & $108(31,361)$ & $114(38,358)$ & $104(22,340)$ & 0.014 \\
\hline Total cholesterol, mean (SD) & $163.6(37.0)$ & $144.9(27.9)$ & $163.1(33.1)$ & $169.6(36.0)$ & $176.7(42.0)$ & $<0.001$ \\
\hline \multicolumn{7}{|l|}{ History of CV risk factors/comorbidities, $n(\%)$} \\
\hline Dyslipidemia & $1,240(78.2)$ & $309(78.0)$ & $302(77.0)$ & $319(80.4)$ & $308(77.6)$ & 0.675 \\
\hline Hypertension & $1,154(72.8)$ & $281(71.0)$ & $279(70.6)$ & $305(76.8)$ & $289(72.8)$ & 0.182 \\
\hline Diabetes mellitus & $552(34.8)$ & $141(35.6)$ & $131(33.2)$ & $139(35.0)$ & $141(35.5)$ & 0.879 \\
\hline Smoking & & & & & & 0.002 \\
\hline Current smoker & $610(38.5)$ & $163(41.2)$ & $156(39.5)$ & $155(39.0)$ & $136(34.3)$ & \\
\hline Previous smoker & $452(28.5)$ & $116(29.3)$ & $122(30.9)$ & $110(27.7)$ & $104(26.2)$ & \\
\hline None & $523(33.0)$ & $117(29.5)$ & $117(29.6)$ & $132(33.2)$ & $157(39.5)$ & \\
\hline Coronary artery disease & $281(17.7)$ & $41(10.4)$ & $49(12.4)$ & $81(20.4)$ & $110(27.7)$ & \\
\hline Cerebrovascular accident & $126(7.9)$ & $29(7.3)$ & $29(7.3)$ & $36(9.1)$ & $32(8.1)$ & \\
\hline Dialysis & $24(1.5)$ & $2(0.5)$ & $3(0.8)$ & $9(2.3)$ & $10(2.5)$ & \\
\hline Peripheral artery disease & $29(1.8)$ & $7(1.8)$ & $7(1.8)$ & $6(1.5)$ & $9(2.3)$ & \\
\hline \multicolumn{7}{|l|}{ LLT at Visit $1(n / N), n(\%)$} \\
\hline Statin & & $385 / 396(97.2)$ & $373 / 395(94.4)$ & $373 / 397(94.0)$ & $356 / 397(89.7)$ & \\
\hline Intensive statin & & $43 / 396(10.9)$ & $27 / 395(6.8)$ & $24 / 397(6.0)$ & $27 / 397(6.8)$ & \\
\hline Ezetimibe & & $18 / 396(4.5)$ & $11 / 395(2.8)$ & $17 / 397(4.3)$ & $16 / 397(4.0)$ & \\
\hline \multicolumn{7}{|l|}{$\begin{array}{l}\text { Change in LDL-C from first measurement after } \\
\text { hospitalization to Visit } 1\end{array}$} \\
\hline Number & & 396 & 395 & 397 & 397 & \\
\hline $\mathrm{mg} / \mathrm{dL}$, mean $(\mathrm{SD})$ & & $-42.3(7.98)$ & $-25.0(4.27)$ & $-9.3(4.44)$ & $13.8(31.57)$ & \\
\hline
\end{tabular}

${ }^{8}$ Evaluated patients with available and changed LDL-C measurement at Visit 1.

\#At first measurement after hospitalization.

Visit 1 was within 14 days of hospitalization for ACS.

ACS, acute coronary syndrome; BMI, body mass index; CV, cardiovascular; eGFR, estimated glomerular filtration rate; HDL-C, high-density lipoprotein cholesterol; LDL-C, low-density lipoprotein cholesterol; LLT, lipid-lowering therapy; SD, standard deviation; STEMI, ST-segmentelevation myocardial infarction; UA, unstable angina. 
Supplementary Table 3. Patient baseline characteristics and lipid profiles, and LLT post ACS and change in LDL-C: subgroup analysis by quartile of absolute LDL-C change from the first measurement after hospitalization to Visit $3^{8}$

\begin{tabular}{|c|c|c|c|c|c|c|}
\hline & $\begin{array}{l}\text { All patients } \\
(n=1,411)\end{array}$ & $\begin{array}{c}\mathrm{Q} 1 \\
(n=328)\end{array}$ & $\begin{array}{c}\mathrm{Q} 2 \\
(n=338)\end{array}$ & $\begin{array}{c}\mathrm{Q} 3 \\
(n=338)\end{array}$ & $\begin{array}{c}\mathrm{Q} 4 \\
(n=337)\end{array}$ & $P$-value \\
\hline Age, years, mean (SD) & $66.0(12.1)$ & $61.4(12.2)$ & $65.7(12.0)$ & $67.2(11.6)$ & $69.5(11.4)$ & $<0.001$ \\
\hline Male, $n(\%)$ & $1,135(80.4)$ & $272(82.9)$ & $274(81.1)$ & $269(79.6)$ & $260(77.2)$ & 0.291 \\
\hline BMI, $\mathrm{kg} / \mathrm{m}^{2}$, mean $(\mathrm{SD})$ & $24.2(3.5)$ & $24.9(3.4)$ & $24.4(3.4)$ & $23.9(3.7)$ & $23.6(3.3)$ & $<0.001$ \\
\hline ACS type, $n(\%)$ & & & & & & 0.007 \\
\hline STEMI & $871(61.7)$ & $228(69.5)$ & $216(63.9)$ & $203(60.1)$ & $188(55.8)$ & \\
\hline UA & $314(22.3)$ & $59(18.0)$ & 63 (18.6) & $75(22.2)$ & $92(27.3)$ & \\
\hline Non-STEMI & $226(16.0)$ & $41(12.5)$ & $59(17.5)$ & $60(17.8)$ & $57(16.9)$ & \\
\hline eGFR $<15 \mathrm{~mL} / \mathrm{min} / 1.73 \mathrm{~m}^{2}, n(\%)$ & $23(1.7)$ & $0(0.0)$ & $3(0.9)$ & $5(1.5)$ & $15(4.5)$ & 0.002 \\
\hline LDL-C, mean (SD), mg/dL, first measurement ${ }^{*}$ & $121.5(39.0)$ & $167.6(33.8)$ & $125.4(19.8)$ & $105.7(22.2)$ & $88.7(25.2)$ & $<0.001$ \\
\hline \multicolumn{6}{|l|}{ Baseline lipid profile (Visit 1), mg/dL } & $<0.001$ \\
\hline HDL-C, mean (SD) & $41.2(11.6)$ & $39.8(11.1)$ & $40.7(10.5)$ & $42.3(12.9)$ & $41.9(11.7)$ & 0.026 \\
\hline Triglycerides, median (min, max) & $108(25,552)$ & $121(31,552)$ & $106(39,337)$ & $106(25,436)$ & $101(36,441)$ & $<0.001$ \\
\hline Total cholesterol, mean (SD) & $164.0(37.2)$ & $183.8(45.3)$ & $162.9(31.0)$ & $156.8(30.9)$ & $151.0(31.0)$ & $<0.001$ \\
\hline \multicolumn{7}{|l|}{ History of CV risk factors/comorbidities, $n$ (\%) } \\
\hline Dyslipidemia & 1,109 (78.6) & $286(87.2)$ & $251(74.3)$ & $251(74.3)$ & $267(79.2)$ & $<0.001$ \\
\hline Hypertension & $1,040(73.7)$ & $224(68.3)$ & $241(71.3)$ & $260(76.9)$ & $262(77.7)$ & 0.014 \\
\hline Diabetes mellitus & $465(33.0)$ & $97(29.6)$ & $101(29.9)$ & $112(33.1)$ & $133(39.5)$ & 0.022 \\
\hline Smoking & & & & & & $<0.001$ \\
\hline Current smoker & $525(37.2)$ & $151(46.0)$ & $127(37.6)$ & $115(34.0)$ & $106(31.5)$ & \\
\hline Previous smoker & $410(29.1)$ & $79(24.1)$ & $110(32.5)$ & $108(32.0)$ & $94(27.9)$ & \\
\hline None & $476(33.7)$ & $98(29.9)$ & $101(29.9)$ & $115(34.0)$ & $137(40.7)$ & \\
\hline Coronary artery disease & $255(18.1)$ & $26(7.9)$ & $39(11.5)$ & $71(21.0)$ & $105(31.2)$ & \\
\hline Cerebrovascular accident & $100(7.1)$ & $20(6.1)$ & $20(5.9)$ & $21(6.2)$ & $31(9.2)$ & \\
\hline Dialysis & $20(1.4)$ & $0(0.0)$ & $4(1.2)$ & $4(1.2)$ & $11(3.3)$ & \\
\hline Peripheral artery disease & $27(1.9)$ & $2(0.6)$ & $3(0.9)$ & $8(2.4)$ & $13(3.9)$ & \\
\hline \multicolumn{7}{|l|}{ LLT at Visit $1(n / N), n(\%)$} \\
\hline Statin & & $321 / 325(98.8) 3$ & $326 / 333(97.9) 3$ & $317 / 331(95.8)$ & 295/334 (88.3) & \\
\hline Intensive statin & & $58 / 325(17.8)$ & $18 / 333(5.4)$ & $27 / 331(8.2)$ & $17 / 334(5.1)$ & \\
\hline Ezetimibe & & $38 / 326(11.7)$ & $17 / 333(5.1)$ & $15 / 331(4.5)$ & $14 / 334(4.2)$ & \\
\hline \multicolumn{7}{|l|}{$\begin{array}{l}\text { Change in LDL-C from first measurement after } \\
\text { hospitalization to Visit } 1\end{array}$} \\
\hline Number & & 328 & 338 & 338 & 337 & \\
\hline $\mathrm{mg} / \mathrm{dL}$, mean $(\mathrm{SD})$ & & $-93.1(25.0)$ & $-51.0(7.7)$ & $-25.6(7.5)$ & $9.5(19.2)$ & \\
\hline
\end{tabular}

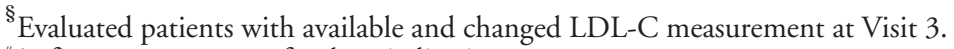

${ }^{\#}$ At first measurement after hospitalization.

Visit 1 was within 14 days of hospitalization for ACS.

ACS, acute coronary syndrome; BMI, body mass index; CV, cardiovascular; eGFR, estimated glomerular filtration rate; HDL-C, high-density lipoprotein cholesterol; LDL-C, low-density lipoprotein cholesterol; LLT, lipid-lowering therapy; SD, standard deviation; STEMI, ST-segmentelevation myocardial infarction; UA, unstable angina. 
Supplementary Table 4. Patient baseline characteristics and lipid profiles, and LLT post ACS and change in LDL-C: subgroup analysis by quartile of percent LDL-C change from the first measurement after hospitalization to Visit $3^{8}$

\begin{tabular}{|c|c|c|c|c|c|c|}
\hline & $\begin{array}{l}\text { All patients } \\
(n=1,411)\end{array}$ & $\begin{array}{c}\mathrm{Q} 1 \\
(n=335)\end{array}$ & $\begin{array}{c}\mathrm{Q} 2 \\
(n=335)\end{array}$ & $\begin{array}{c}\mathrm{Q} 3 \\
(n=335)\end{array}$ & $\begin{array}{c}\mathrm{Q} 4 \\
(n=336)\end{array}$ & $P$-value \\
\hline Age, years, mean (SD) & $66.0(12.1)$ & $62.3(12.6)$ & $65.3(12.0)$ & $67.2(11.6)$ & $69.2(11.4)$ & $<0.001$ \\
\hline Male, $n(\%)$ & $1,135(80.4)$ & $281(83.9)$ & $279(83.3)$ & $262(78.2)$ & $253(75.3)$ & 0.013 \\
\hline BMI, $\mathrm{kg} / \mathrm{m}^{2}$, mean $(\mathrm{SD})$ & $24.2(3.5)$ & $24.9(3.4)$ & $24.5(3.4)$ & $23.7(3.5)$ & $23.6(3.3)$ & $<0.001$ \\
\hline ACS type, $n(\%)$ & & & & & & 0.007 \\
\hline STEMI & $871(61.7)$ & $231(69.0)$ & $214(63.9)$ & $203(60.6)$ & $187(55.7)$ & \\
\hline UA & $314(22.3)$ & $62(18.5)$ & $64(19.1)$ & $73(21.8)$ & $90(26.8)$ & \\
\hline Non-STEMI & $226(16.0)$ & $42(12.5)$ & $57(17.0)$ & $59(17.6)$ & $59(17.6)$ & \\
\hline $\mathrm{eGFR}<15 \mathrm{~mL} / \mathrm{min} / 1,73 \mathrm{~m}^{2}, n(\%)$ & $23(1.7)$ & $0(0.3)$ & $2(0.6)$ & $5(1.5)$ & $15(4.6)$ & 0.007 \\
\hline LDL-C, mean (SD), mg/dL, first measurement ${ }^{*}$ & $121.5(39.0)$ & $153.1(38.6)$ & $129.7(32.7)$ & $111.5(27.7)$ & $91.9(26.8)$ & $<0.001$ \\
\hline \multicolumn{7}{|c|}{ Baseline lipid profile (Visit 1), mg/dL } \\
\hline LDL-C, mean (SD), calculated & $98.8(30.9)$ & $107.7(36.8)$ & $100.7(30.8)$ & $95.4(25.4)$ & $89.6(26.5)$ & $<0.001$ \\
\hline HDL-C, mean (SD) & $41.2(11.6)$ & $39.6(10.9)$ & $40.6(11.2)$ & $42.5(12.6)$ & $42.0(11.7)$ & 0.004 \\
\hline Triglycerides, median (min, max) & $108(25,552)$ & $117(31,408)$ & $106(35,552)$ & $107(25,436)$ & $101(36,441)$ & $<0.001$ \\
\hline Total cholesterol, mean (SD) & $164.0(37.2)$ & $173.3(41.8)$ & $165.7(39.1)$ & $161.4(32.0)$ & $153.7(31.7)$ & $<0.001$ \\
\hline \multicolumn{7}{|l|}{ History of CV risk factors/comorbidities, $n(\%)$} \\
\hline Dyslipidemia & $1,109(78.6)$ & $275(82.1)$ & $262(78.2)$ & $249(74.3)$ & $269(80.1)$ & 0.089 \\
\hline Hypertension & $1,040(73.7)$ & $232(69.3)$ & $238(71.0)$ & $257(76.7)$ & $260(77.4)$ & 0.036 \\
\hline Diabetes mellitus & $465(33.0)$ & $104(31.0)$ & $104(31.0)$ & $100(29.9)$ & $135(40.2)$ & 0.015 \\
\hline Smoking & & & & & & 0.006 \\
\hline Current smoker & $525(37.2)$ & $149(44.5)$ & $120(35.8)$ & $121(36.1)$ & $109(32.4)$ & \\
\hline Previous smoker & $410(29.1)$ & $86(25.7)$ & $113(33.7)$ & $100(29.9)$ & $92(27.4)$ & \\
\hline None & $476(33.7)$ & $100(29.9)$ & $102(30.4)$ & $114(34.0)$ & $135(40.2)$ & \\
\hline Coronary artery disease & $255(18.1)$ & $28(8.4)$ & $47(14.0)$ & $66(19.7)$ & $100(29.8)$ & \\
\hline Cerebrovascular accident & $100(7.1)$ & $18(5.4)$ & $21(6.3)$ & $21(6.3)$ & $32(9.5)$ & \\
\hline Dialysis & $20(1.4)$ & $1(0.3)$ & $2(0.6)$ & $5(1.5)$ & $11(3.3)$ & \\
\hline Peripheral artery disease & $27(1.9)$ & $3(0.9)$ & $3(0.9)$ & $7(2.1)$ & $13(3.9)$ & \\
\hline \multicolumn{7}{|l|}{ LLT at Visit $1(n / N), n(\%)$} \\
\hline Statin & & 329/333 (98.8) & $322 / 328(98.2)$ & $314 / 329(95.4)$ & $294 / 333(88.3)$ & \\
\hline Intensive statin & & $59 / 333(17.7)$ & $18 / 328(5.5)$ & $26 / 329(7.9)$ & $17 / 333(5.1)$ & \\
\hline Ezetimibe & & $37 / 333(11.1)$ & $19 / 329(5.8)$ & $14 / 329(4.3)$ & $14 / 333(4.2)$ & \\
\hline \multicolumn{7}{|l|}{$\begin{array}{l}\text { Change in LDL-C from first measurement after } \\
\text { hospitalization to Visit } 1\end{array}$} \\
\hline Number & & 335 & 335 & 335 & 336 & \\
\hline $\mathrm{mg} / \mathrm{dL}$, mean $(\mathrm{SD})$ & & $-57.6(7.29)$ & $-40.5(4.30)$ & $-23.8(5.94)$ & $12.7(24.44)$ & \\
\hline
\end{tabular}

${ }^{\S}$ Evaluated patients with available and changed LDL-C measurement at Visit 3.

${ }^{*}$ At first measurement after hospitalization.

Visit 1 was within 14 days of hospitalization for ACS.

ACS, acute coronary syndrome; BMI, body mass index; CV, cardiovascular; eGFR, estimated glomerular filtration rate; HDL-C, high-density lipoprotein cholesterol; LDL-C, low-density lipoprotein cholesterol; LLT, lipid-lowering therapy; SD, standard deviation; STEMI, ST-segmentelevation myocardial infarction; UA, unstable angina. 